\title{
EDITORIAL
}

\section{Happy 2012!}

DOI: http://dx.doi.org/10.5770/cgj.15.32

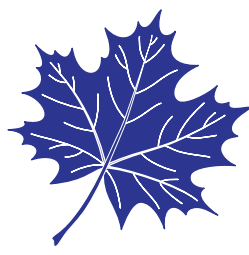

Along with less snow and blooming crocuses, another sign of winter's retreat is the spring issue of the Canadian Geriatrics Journal. We are pleased to present a series of articles that investigate gerontological issues in a series of different environments including acute care, the classroom, and the ambulance bay.

Dr. McAiney has performed a detailed examination of the prevalence of delirium in a hospital setting. Hirst et al. have studied the amount of geriatric content in Canadian nursing and social work degree programs. A narrative systematic review of the concept of frailty in the prehospital setting is presented by Goldstein et al

We hope you enjoy our spring issue!

Ken Madden, Editor-in-Chief, Canadian Geriatrics Journal 